\title{
Tumor Cell to Total Cell Ratio Measurement
}

National Cancer Institute

\section{Source}

National Cancer Institute. Tumor Cell to Total Cell Ratio Measurement. NCI Thesaurus.

Code C127771.

The determination of the ratio of tumor cells compared to total cells present in a sample.

The measurement may be expressed as a ratio or percentage. 